\title{
Application of UAV and Csp1 Matrix for Building Inspection at Muzium Negeri, Seremban
}

\author{
Siti Nooraiin Mohd Razali, Masiri Kaamin, Siti Noraiza Ab Razak, Nor Baizura Hamid, Nor Farah \\ Atiqah Ahmad, Mardiha Mokhtar, Norhayati Ngadiman, Suhaila Sahat
}

\begin{abstract}
Building inspection is really essential to determine the condition of a building and one of the key components of building maintenance. To determine the defect, visual inspection will be conducted as early phase of building inspection. Usually, binocular and camera will be used as main devices in visual inspection. This research aims to study Museum Negeri defects at exterior structure especially the roof structure by using the Unmanned Aerial Vehicles (UAV) or as known as Drone. The data collected will be analyzed using Condition Survey Protocol 1 Matrix to obtain an overall rating of the building's condition. The process involved in this study are site visit, planning and preparation before the flight, data collection using $U A V$, image processing and analyzing data from image. The results of analysis, a total numbers of 53 locations have been identified and documented suffer from defects or faults such as cracking, corrosion and wall perforated. All defects information obtained using $U A V$ visual inspection can help the museum maintenance to do maintenance work. The overall condition of this building structure is 5 , where the overall performance of the building is fair.
\end{abstract}

Index Terms: Building inspection, drone, CSP1.

\section{INTRODUCTION}

Building inspection can be defined as an investigation and assessment of the construction and condition of a building. It is really essential to determine the condition of a building and one of the key components of building maintenance. Usually, it is covering all the structure of building such as wall and roof. By doing inspection, the defects of building can be detected and maintenance will be conducted.

This research focus on using high resolution of camera digital by UAV as one platform to collect data by taking photos and videos [1]. Conventionally, the building

Revised Manuscript Received on July 12, 2019

Siti Nooraiin Mohd Razali, Centre for Diploma Study, UTHM, Johor, Malaysia

Masiri Kaamin, Centre for Diploma Study, UTHM, Johor, Malaysia.

Siti Noraiza AB Razak, Centre for Diploma Study, UTHM, Johor, Malaysia.

Nor Baizura Hamid, Centre for Diploma Study, UTHM, Johor, Malaysia. Nor Farah Atiqah Ahmad, Centre for Diploma Study, UTHM, Johor, Malaysia

Mardiha Mokhtar, Centre for Diploma Study, UTHM, Johor, Malaysia

Norhayati Ngadiman, Centre for Diploma Study, UTHM, Johor, Malaysia Suhaila Sahat, Centre for Diploma Study, UTHM, Johor, Malaysia inspection only done by taking photos using camera or observation. Documentation of Photography conducted using stairs for higher parts of structure and taking photos directly [2]. The objectives for this case study are to explore method of inspection conducted for exterior building and to analyze and record the data more details using UAV. Thus, UAV has being used as alternative way to collecting and recording the data by visual easily. From the data, analysis process for building's defects can be analyzed and the ways for maintenance can be planned using CSP1 Matrix to avoid the defects from getting worse.

Unique aesthetics value for one country can be seen from the structural design for its building. Museum of Negeri Sembilan is chosen because its unique value especially the roof which shows Minangkabau design. Muzium Negeri or known as Teratak Perpatih located in Seremban, Negeri Sembilan. This building was a pavilion for Tilawah Al-Quran Ceremony in previous time. This building is the only one pavilion for this ceremony that have been modified and still intact till today [3]. In 1981, Teratak Perpatih has been declared as Muzium Negeri to replace Istana Ampang Tinggi by YAB Dato' Mohd Isa Bin Haji Abdul Samad which was the minister of Negeri Sembilan at that time [4] Fig. I shows Muzium Negeri as the location of case study This historical building need to be well preserve because its historical value for the nation. Therefore, the condition of this building critical to be inspect for the maintenance purpose.

\section{LITERATURE REVIEW}

Inspection of the building and damage known as dilapidation study. It is a process to identify and record the condition or degree of disability of the building. This study is a practice of documenting the problems and defects of the building [5]. The assessment of an old building getting more emphasize to ensure that the building is still intact. It also can be defined as assessment of performance as matrix system that have been used to determine efficiency [6]. Inspection is a process to determine the quality for a product or service to achieve the standard that have been assigned [7]. Every organization has maintenance policy in order to enhance all the quality aspects of the building [8]. 


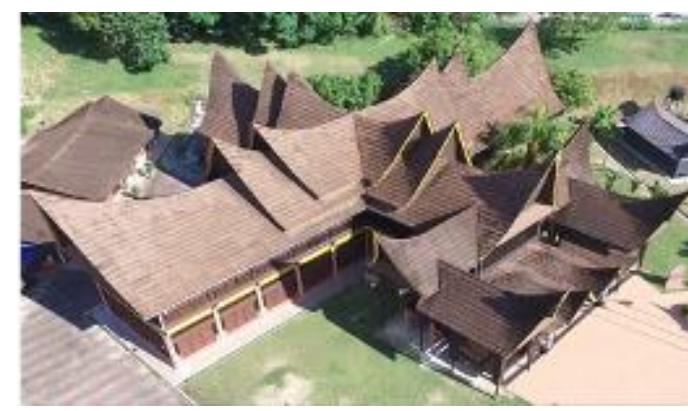

Fig. I: Muzium Negeri in Seremban, Negeri Sembilan.

\section{A. Unmanned Aerial Vehicle (UAV)}

Micro Unmanned Aerial Vehicle (UAV) or also known as drone is equipped with a camera that offers the possibility to map the different areas quickly and with high flexibility compares to classic aerial photography [9]. It is also known as the Autonomous Navigation system because it is fly by using Global Positioning System (GPS) and support by the telemetry systems at the Ground Control Station (GCS) to monitor and navigate the UAV when capturing the data [10]. DJI Phantom 3 Advanced and DJI Phantom 4 Pro used for this research as alternative ways for collecting data visually. The use of UAV micro-driver aircraft is an alternative to visually inspecting high-rise exterior structures more easily, quickly and frequently by providing building information for the building maintenance works without use so much of manpower [11].

\section{B. Condition Survey Protocol (CSP) 1 Matrix System}

The Condition Survey Protocol 1 (CSP1) Matrix was developed as a rating tool for a reasonable property condition assessment. The matrix is also suitable for all types of buildings because the data input relies on the condition of building and damage assessments [12]. Analysis from these information produce the index for performance of the building. The aim of CSP1 Matrix to enable the surveyors to collect data within shortest possible time. Besides, to record the existing defects of the building, the main source of data, by assessing the condition and assigning priority to each defect recorded and to obtain an overall rating of the building's condition.

Scale value of condition and priority will be given based on damage record as shown in Table 1 and Table 2. These value will be multiplied to determine the total score for each defect as shown in Table 3. The alphabet $\mathrm{R}$ refer to red, Y refer to yellow and $G$ refer to green. This method of analysis makes it easy to identify the level of seriousness of each defect recorded during the building inspection. The descriptive value according to the score as in Table 4 .

The overall of building rating will be calculated to summarize the building condition. The score of each defect is added up and after that will be divided by the total number of defects to get the overall building rating. Table 5 shows the overall building ratings.
Table 1: Condition Assessment Protocol 1 [12]

\begin{tabular}{|c|l|l|}
\hline Condition & Scale Value & Description \\
\hline 1 & Good & Minor servicing \\
\hline 2 & Fair & Minor Repair \\
\hline 3 & Poor & Major Repair/Replacement \\
\hline 4 & Very Poor & Malfunction \\
\hline 5 & Dilapidated & $\begin{array}{l}\text { Damage/Replacement of } \\
\text { Missing Part }\end{array}$ \\
\hline
\end{tabular}

Table 2: Priority Assessment [12]

\begin{tabular}{|c|l|l|}
\hline $\begin{array}{l}\text { Priorit } \\
\mathbf{y}\end{array}$ & $\begin{array}{l}\text { Scale } \\
\text { Value }\end{array}$ & Description \\
\hline 1 & Normal & Functional; cosmetic defect only \\
\hline 2 & Routine & $\begin{array}{l}\text { Minor defect, but could become } \\
\text { serious if left unattended }\end{array}$ \\
\hline 3 & Urgent & $\begin{array}{l}\text { Serious defect, doesn't function at } \\
\text { an acceptable standard }\end{array}$ \\
\hline 4 & Emergency & $\begin{array}{l}\text { Element/Structure doesn't function } \\
\text { at all; OR Presents risks that could } \\
\text { lead to fatality and/or injury }\end{array}$ \\
\hline
\end{tabular}

Table 3: Matrix [12]

\begin{tabular}{|c|c|c|c|c|c|}
\hline \multicolumn{2}{|l|}{ Scale } & \multicolumn{4}{|c|}{ Priority Assessment } \\
\hline & & E4 & U3 & $\mathbf{R 2}$ & N1 \\
\hline \multirow{5}{*}{$\begin{array}{l}\text { Condition } \\
\text { Assessment }\end{array}$} & 5 & $20(\mathbf{R})$ & $15(\mathbf{R})$ & $10(Y)$ & $5(Y)$ \\
\hline & 4 & $16(\mathrm{R})$ & $12(Y)$ & $8(Y)$ & $4(G)$ \\
\hline & 3 & $12(Y)$ & $9(\mathbf{Y})$ & $6(Y)$ & $3(G)$ \\
\hline & 2 & $8(Y)$ & $6(Y)$ & $4(G)$ & $2(G)$ \\
\hline & 1 & $4(G)$ & $3(G)$ & $2(G)$ & $1(G)$ \\
\hline
\end{tabular}

Table 4: The Descriptive Value According to Score [12]

\begin{tabular}{|c|l|c|}
\hline No. & \multicolumn{1}{|c|}{ Matrix } & Score \\
\hline 1 & Planned Maintenance & 1 to 4 \\
\hline 2 & Condition Monitoring & 5 to 12 \\
\hline 3 & Serious Attention & 13 to 20 \\
\hline
\end{tabular}

Table 5: Overall Building Rating [11]

\begin{tabular}{|c|l|c|}
\hline No. & \multicolumn{1}{|c|}{ Building Rating } & Score \\
\hline 1 & Good & 1 to 4 \\
\hline 2 & Fair & 5 to 12 \\
\hline 3 & Dilapidated & 13 to 20 \\
\hline
\end{tabular}

\section{METHODOLOGY}

The methodology covers the method used to achieve the objectives of the study. Enhanced defect identification system will consist of three operating procedures using unmanned aerial vehicles and Condition Survey Protocol 1 Matrix for disability level analysis.

\section{A. Planning and Preparation}

Flight planning for UAV micro aircraft in the Muzium Negeri is provided to ensure data retrieval and information are easily implemented. For more efficient inspection path, the inspector will plan on inspecting the floors one by one. The flight plan will be planned to capture defects that are unreachable from the interior framing of the building. The 
distances between the UAV micro aircraft and the building wall using DJI G0 have been set about $2 \mathrm{~m}$. The Fig. II shows in using Pix4D Capture, the period of UAV aircraft flew have been set about 6 minutes 30 seconds with the distance between UAV and the roof is 4 metres and 16 metres from the ground. The areas of location for fly have been set about $32 \mathrm{~m}$ $\times 49 \mathrm{~m}$ with the angle of the camera is $60^{\circ}$. The front overlap and side overlap was set about $70 \%$ and $80 \%$ with the aircraft speed is slow.

\section{B. Data Collection}

Captures the image using UAV camera was the method of collecting data. The UAV aircraft are made manually fly using DJI GO application for the wall building, so that pictures obtained are more quality and clearly visible and can identify any defects on the wall.

Due to the complex roof shape, auto capture is used by taking pictures from every angle of the roof using Pix4D Captures application. The Fig. III shows of an unmanned aerial vehicles flight plan for surveying the roof building and the total images is 60 images. For the wall building, the total image is 425 images. This result shows that the planning and preparation are successful as planned. The Fig. IV shows the UAV operator in controlling the remote control.

\section{Processing Data}

From the image have been taken, the images will be transferred from the UAV flight into the laptop for processing to get the high quality images. In this process, photogrammetry method is used in processing the roof images. The images taken for the roof will be process to get a complete image covering the entire of roof plan using the Pix4DMapper software. The Fig. V shows the images of roof building were processing in high quality result. Then, the complete image of roof building will be transfer into Global Mapper software and will be zooming in the display clearly to get the size and coordinate of the defects. The Fig. VI shows that the images were processing using the Global Mapper software.

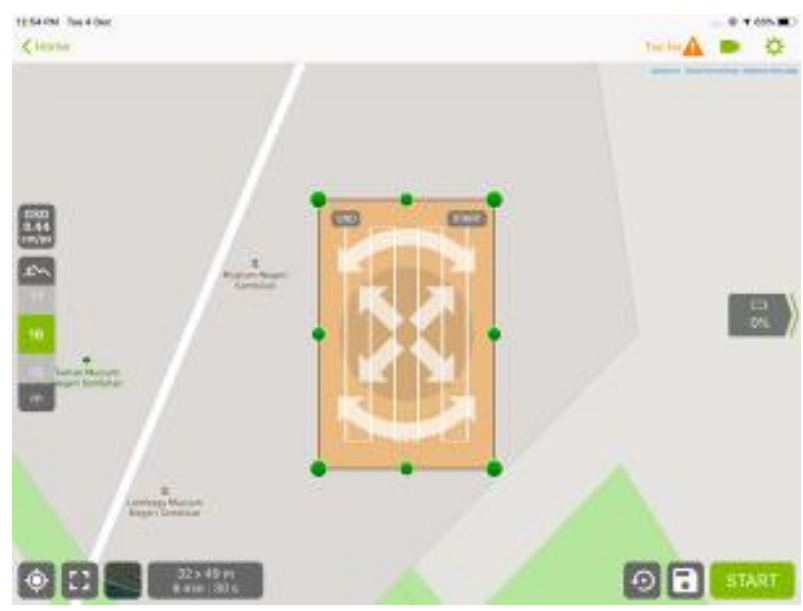

Fig. II: The coverage of study site have been set and ready to fly.

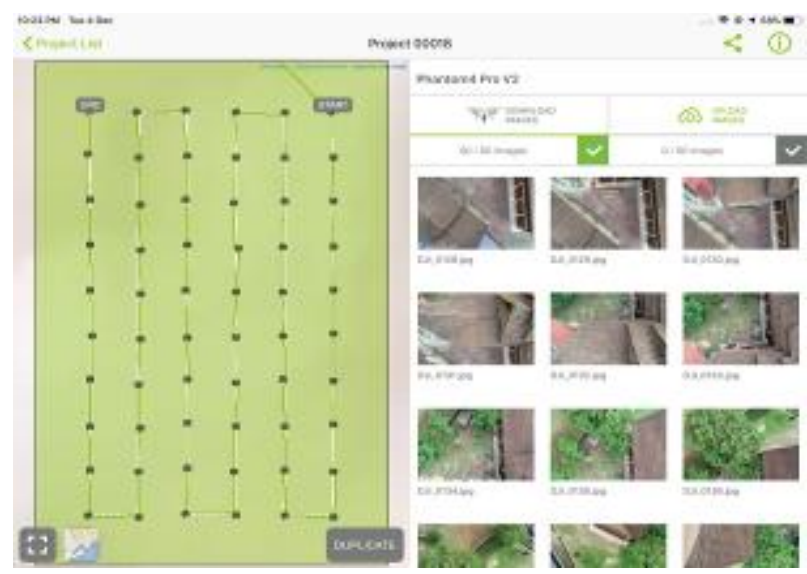

Fig. III: The movement of aircraft using Pix4D Capture

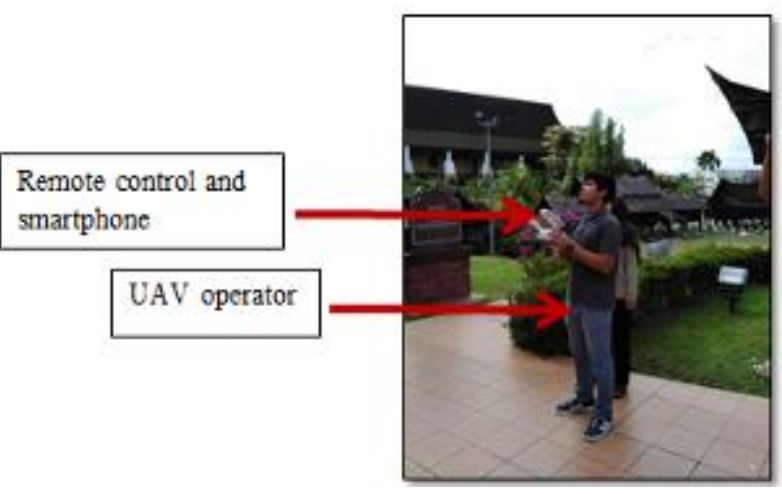

Fig. IV: The process of data collection.
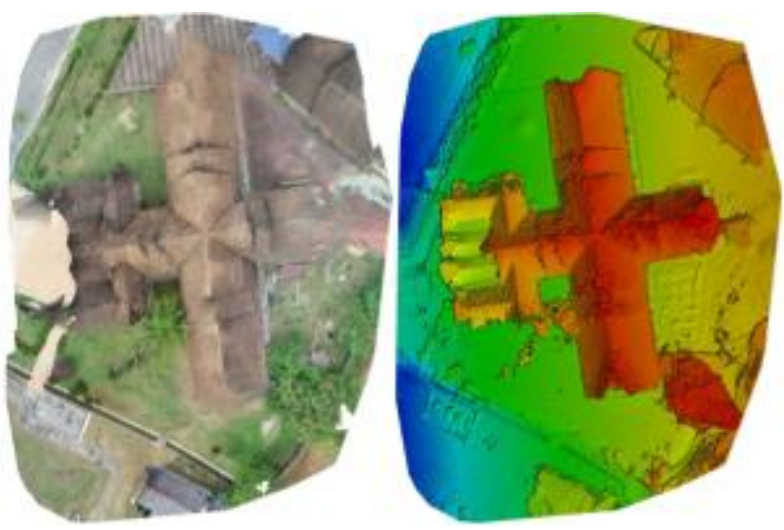

Fig. V: The process of roof images using Pix4D Mapper.

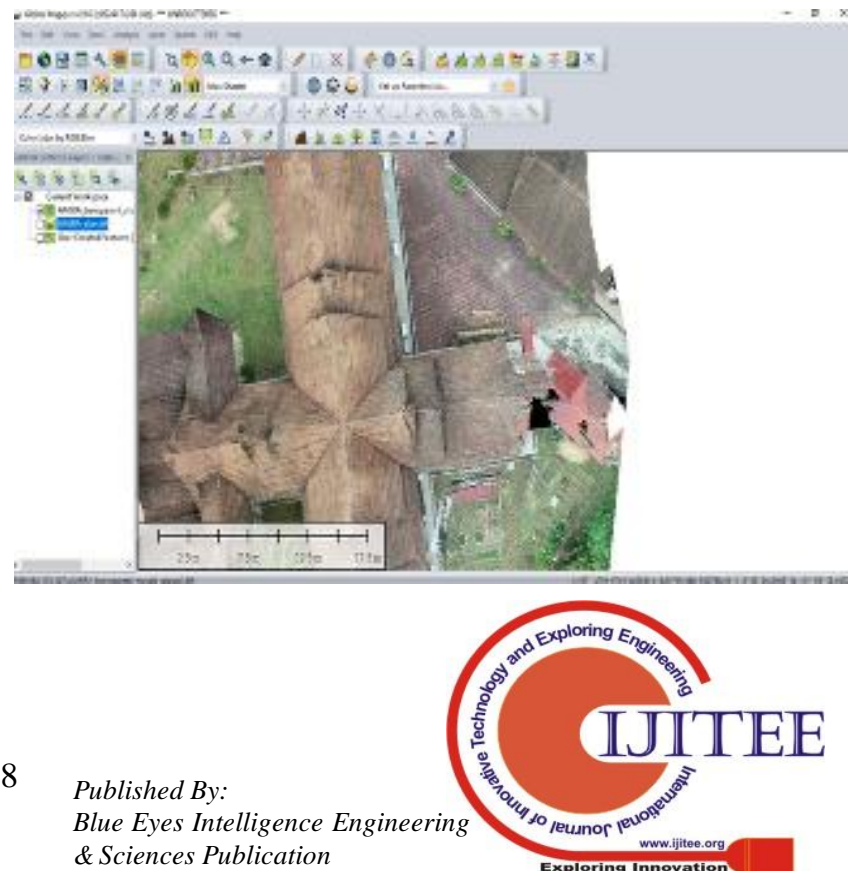


Fig. VI: The processing of images using Global Mapper software.

\section{DATA AND ANALYSIS}

All the entire images then will be undergoes the determination of the defect by using the Condition Survey Protocol (CSP) 1 Matrix. For more details on how CSP1 Matrix rating can refer to previous study by the author where using CSP1 matrix for building inspection at mosques in area of Pagoh - Muar, Johor [13]. Instead of a longhand description of a building's defects, this matrix requires concise explanations about the defects identified, thus saving on-site time during a building inspection. The full score is used to give the building an overall rating which is Good, Fair or Dilapidated. In CSP1 Matrix consist of original image and then image after zooming process. Coordination of the defects have been set from the process in GlobalMapper software. The defect of the structure in Table 6 and Table 7 can be located by refer to the Fig. VII while the defect of structure in Table 8 and Table 9 can be located by refer to the Fig. VIII.

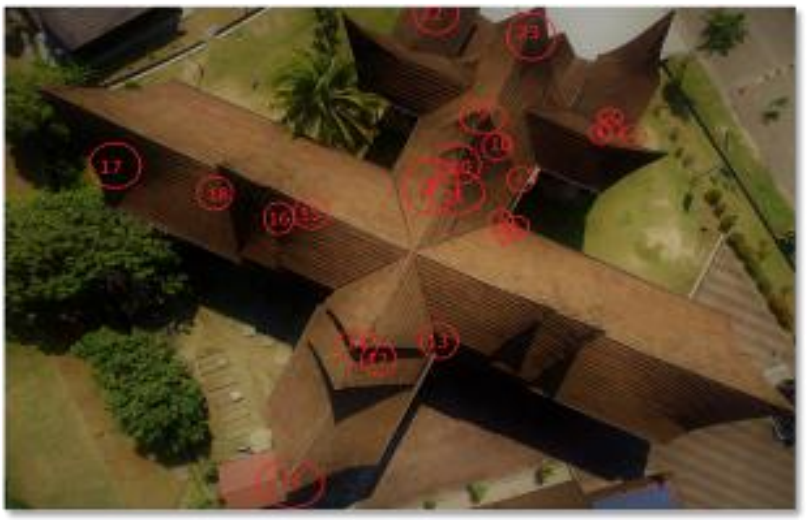

Figure VII: The location of defects for roof

Table 6: CSP1 Matrix analysis for roof building (image 17)

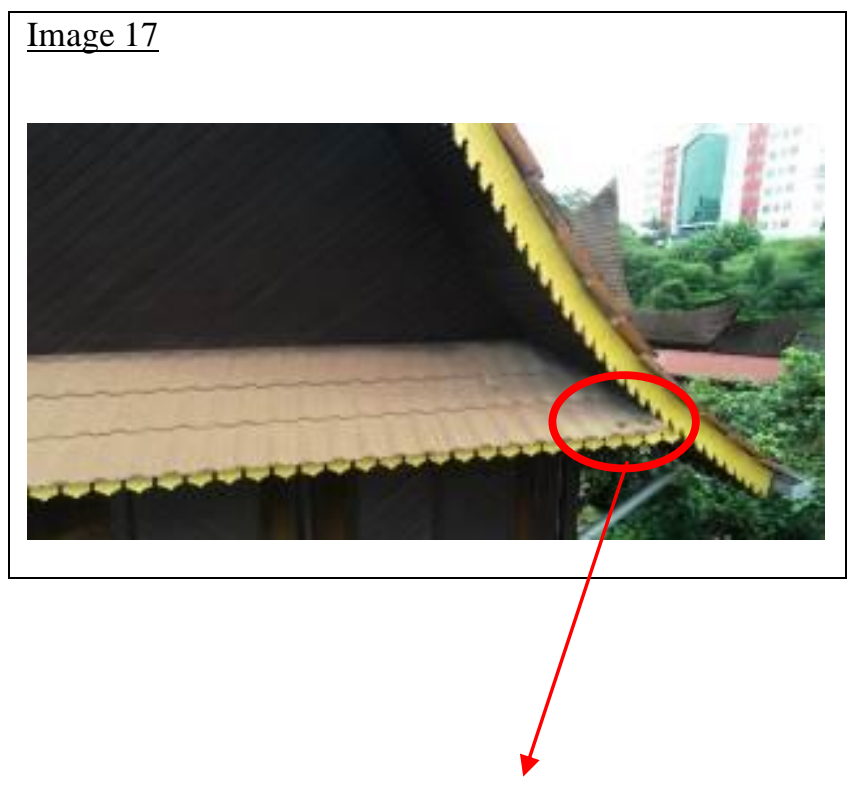

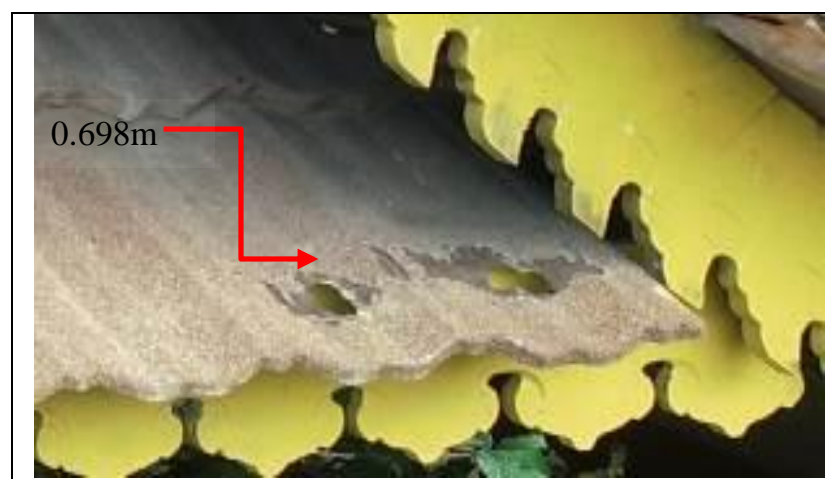

\section{CSP1 Details}

Number of Defects : 1

Coordinate : $3^{1933}{ }^{\circ} \mathrm{N}, 14.1619^{\circ} \mathrm{E}$

\begin{tabular}{|c|c|c|c|}
\hline Condition & Priority & Matrix & Colour \\
\hline $\mathbf{5}$ & $\mathbf{3}$ & $\mathbf{1 5}$ & RED \\
\hline
\end{tabular}

Element / components : Roof

Description of Defects : Perforated roof

Suggestion : replace the new roof

Table 7: CSP1 Matrix analysis for roof building (image 22)

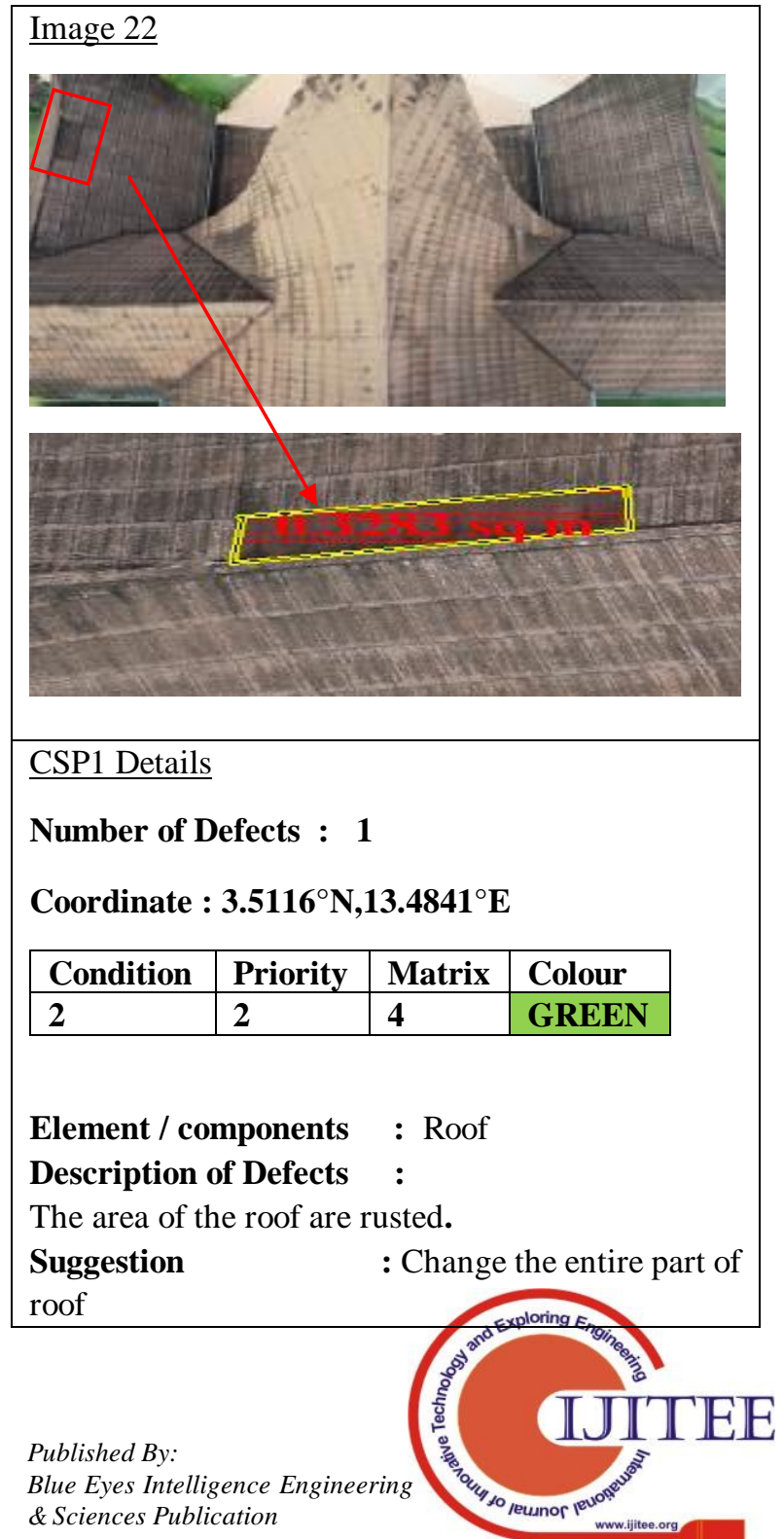




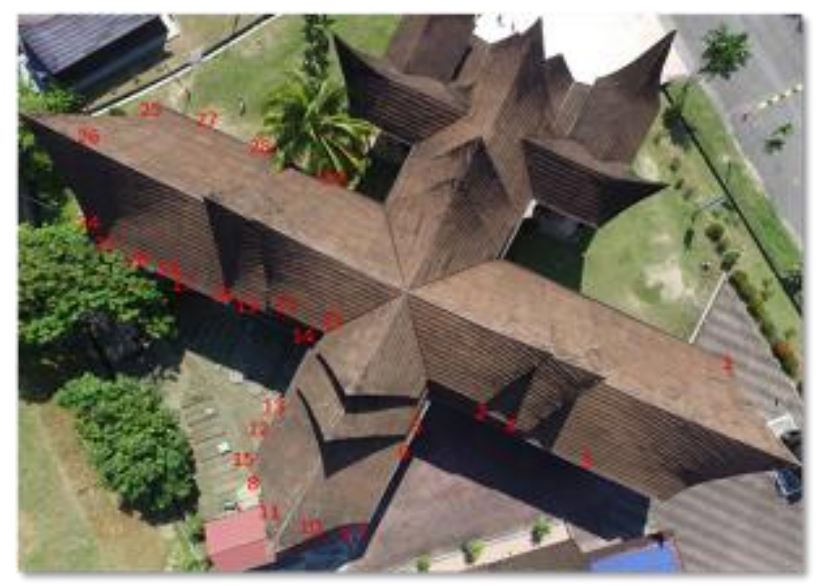

Fig. VIII: Location of defects for walls

Table 8: CSP1 Matrix analysis for wall building (image 16)

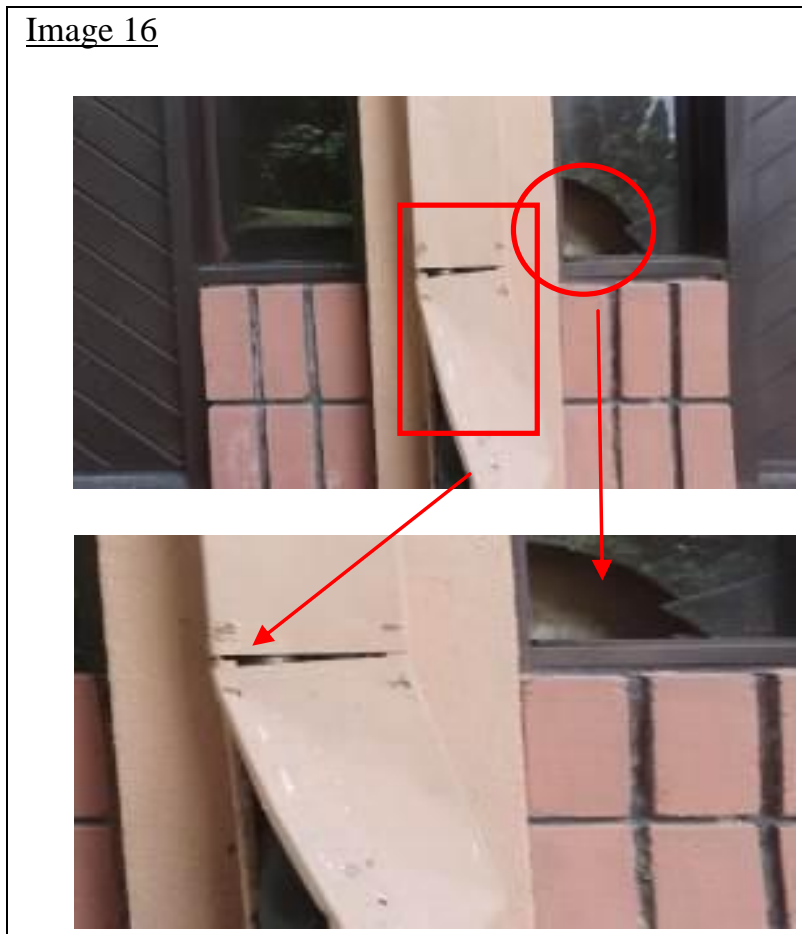

CSP1 Details

Number of Defects : 1

Coordinate $: 3^{1933}{ }^{\circ} \mathrm{N}, 14.1619{ }^{\circ} \mathrm{E}$

\begin{tabular}{|c|c|c|l|}
\hline Condition & Priority & Matrix & Colour \\
\hline 2 & $\mathbf{3}$ & $\mathbf{6}$ & YELLOW \\
\hline
\end{tabular}

Element / components : Glass wall and wire box

Description of Defects : crack

Suggestion

Replace the glass with the new one and make sure the wire's box in good condition.
Table 9: CSP1 Matrix analysis for wall building (image 13)

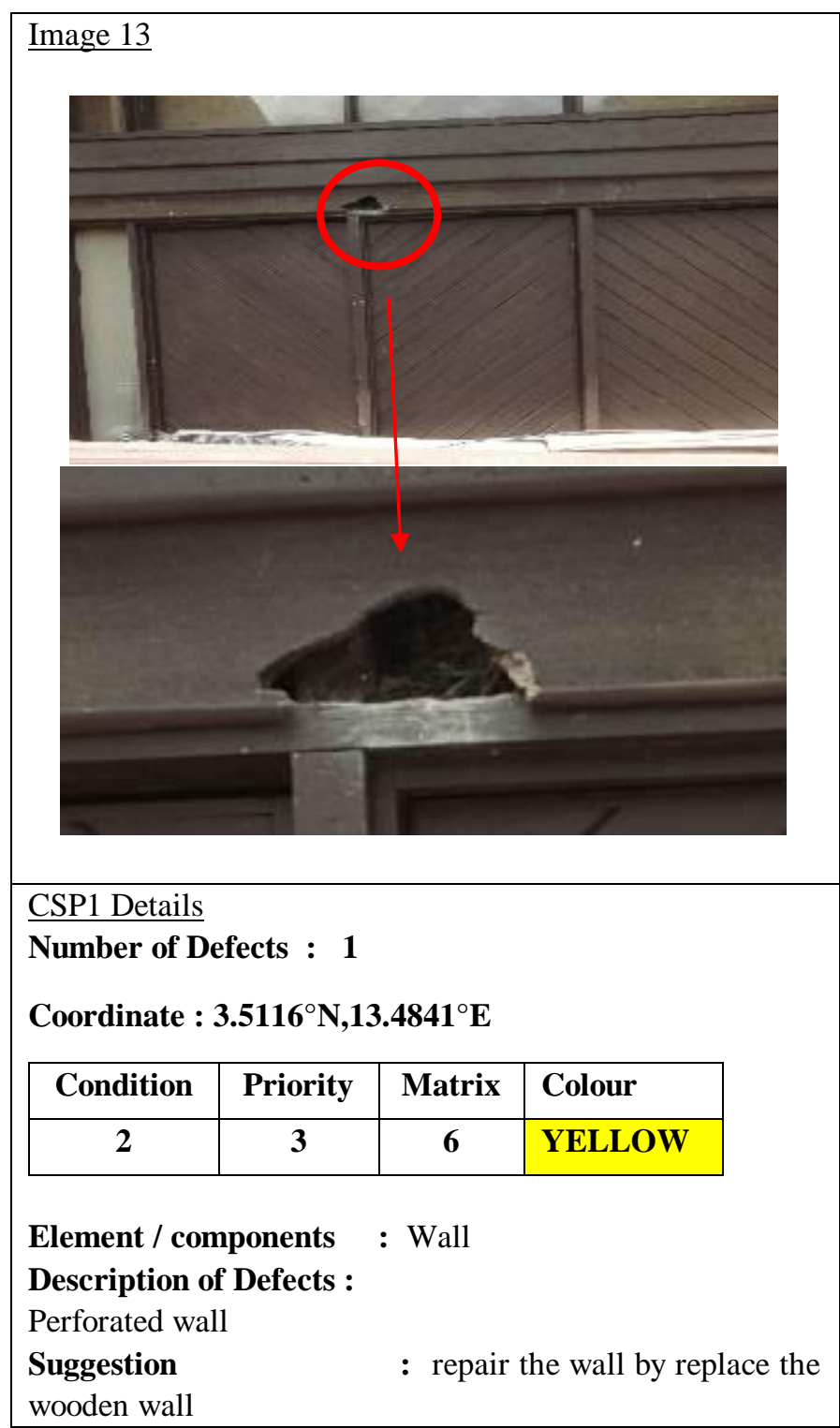

The table 10 shows the overall number of defects for every type of defect in exterior of museum structure which is roof and wall building.

Table 10 Type of defects in overall side of building

\begin{tabular}{|c|c|c|c|}
\hline \multicolumn{2}{|c|}{$\begin{array}{l}\text { Structure of } \\
\text { buildings }\end{array}$} & Type of defects & $\begin{array}{l}\text { Number of } \\
\text { defects }\end{array}$ \\
\hline \multirow{6}{*}{\multicolumn{2}{|c|}{ Roof }} & Mossy & 6 \\
\hline & & Deprived nails & 4 \\
\hline & & Rusted & 6 \\
\hline & & Break & 3 \\
\hline & & Perforated & 1 \\
\hline & & Decay & 4 \\
\hline \multirow{6}{*}{\multicolumn{2}{|c|}{$\begin{array}{l}\text { Right } \\
\text { side }\end{array}$}} & Perforated & 3 \\
\hline & & Scattered wire & 2 \\
\hline & & Rupture window & 2 \\
\hline & & Faded paint & 2 \\
\hline & & Eroded walls & 1 \\
\hline & & Deprived lamp & \\
\hline
\end{tabular}




\begin{tabular}{|l|l|l|l|}
\hline \multirow{4}{*}{$\begin{array}{l}\text { Wal } \\
\mathbf{l}\end{array}$} & Backside & Crack timber walls & 1 \\
\cline { 3 - 4 } & No timber barrier & 1 \\
\cline { 3 - 4 } & Deprived timber wall & 1 \\
\cline { 3 - 4 } & White line & 1 \\
\cline { 3 - 4 } & \multirow{4}{*}{ Left side } & $\begin{array}{l}\text { Rupture window and } \\
\text { wire's box }\end{array}$ & 6 \\
\cline { 3 - 3 } & Scattered wire & 2 \\
\cline { 3 - 4 } & Paint spill & 1 \\
\cline { 3 - 4 } & Rusted water drainage & 1 \\
\hline & Perforated timber wall & 2 \\
\hline & Timber wall crack & 1 \\
\hline & Deprived timber wall & 1 \\
\hline
\end{tabular}

Table 11 Colour of CSP1 Matrix for roof

\begin{tabular}{|l|l|}
\hline Colour & Images number \\
\hline$(\mathrm{R})$ & 17,24 \\
\hline & $2,9,14,18,20,21,23$ \\
\hline & $1,3,4,5,6,7,8,10,11,12,13,15,16,19,22$ \\
\hline
\end{tabular}

Table 12 Colour of CSP1 Matrix for wall

\begin{tabular}{|l|l|}
\hline Colour & Images number \\
\hline & - \\
\hline & $1,2,4,5,8,9,13,14,16,17,27,29$ \\
\hline & $3,6,7,10,11,12,15,18,19,20,21,22,23,24,25,26,28$ \\
\hline
\end{tabular}

The overall of building rating will be calculated to summarize the building condition. The score of each defect is added up and after that will be divided by total number of defects to get the overall building rating. Below shows the calculation for building rating.

Calculation:

Overall Building Rating

$=\underline{\text { Total Score Matrix for Roof }+ \text { Total Score Matrix for Wall }}$ Number of Defects

$=(148+121) /(24+29)$

$=5$

So, based on table 5, the overall building rating for Muzium Negeri is 5 which categorized as fair.

\section{CONCLUSIONS}

The study was conducted to identify the damage and defects on the building structure in Muzium Negeri, Seremban, Negeri Sembilan. Generally, almost all types of building are not detached from having defects even though it was newly built. This has caused the aesthetic value of the building, causing interference and threats safety to the visitors. This study also introduces the application of the micro UAV aircraft as an alternative method obtaining the clear defects especially in high ground. It is suitable with the development of technology nowadays in buildings inspection. The CSP 1 Matrix is using as rating tool for a reasonable property condition assessment. These can help to know the level of damage for every defect whether it is in good condition or urgent repairs needed. As a result of the study, about 24 areas of roof building and 29 areas at wall building which defect have been identified. With that, early prevention is needed to minimize the risk of structure damage. The Department of Museums Malaysia and Muzium Negeri shall cooperate in preserving the building structure of the museum building. It is because the older the age of building or the structure, the more defect can be detected.

\section{ACKNOWLEDGMENT}

This research has funded by grant FRGS, vote 1620. The authors would like to thanks to Research Management Centre (RMC), UTHM. The extended gratitude to Razerim Anak Razak, Nurul Amshahiera Mazlan, Amira Balqish Sukri for accomplished this study.

\section{REFERENCES}

A. A (2009). Mapping using small format digital imagery and unmanned aerial vehicle platform.

2. A. G. Ahmad (2004). Understanding common building defects: the dilapidation survey report.

3. Z. Sharuddin (2016) Understanding common building defects: the dilapidation survey report.

4. L. M. N. Sembilan, Sejarah Penubuhan Muzium Negeri.

A. G. Ahmad (2006). Rangka Kerja Pemuliharaan Bangunan Warisan di Malaysia.

6. A. K. Parida (2006). Maintenance Performance Measurement (MPM): Issues and Challenges. J. Qual. Maint. Eng. 12(3): 239-251.

7. A. \&. A. A. A. R. Olanweraju (2015). Building maintenance processes, principles, procedures, practices and strategies. In Building Maintenance Processes and Practices(pp. 79-129).

8. Yacob (2005). Maintenance Management System through Strategic Planning for Public School in Malaysia, in Construction Management.

9. J. R. M. \&. H. C. Unger(2014). UAV-based photogrammetry: monitoring of a building zone. International Archives of the Photogrammetry, Remote Sensing and Spatial Information Sciences-ISPRS Archives 40 (2014), 40(5), 601-606.

10. N. A. A. \&. Z. O. Darwin(2014). The potential of unmanned aerial vehicle for large scale mapping of coastal area. In IOP Conference Series: Earth and Environmental Science (Vol. 18, No. 1, p. 012031). IOP Publishing.

11. Masiri Kaamin, Nurunnazifah Abd. Aziz, Saifullizan Mohd Bukari, Zaurin Ali, Norhafiza Samion, Aslila Abd Kadir, Norhayati Ngadiman. (2016). KAEDAH PEMERIKSAAN BANGUNAN TINGGI MENGGUNAKAN PESAWAT TANPA PEMANDU (UAV). Jurnal Teknologi. 78: 5-10; 83-89

12. A. T. A. K. K. Che Ani (2011). The Development of a Condition Survey Protocol Matrix. Structural Survey, 29(1), 35-45.

13. M. Mokhtar, M. Kaamin, N. Ngadiman, \& N. B. Hamd (2018). The application of UAV and CSP1 matrix for building inspection at mosques in area of Pagoh - Muar, Johor. AIP Conference Proceedings, Vol. 2016. 


\section{AUTHORS PROFILE}

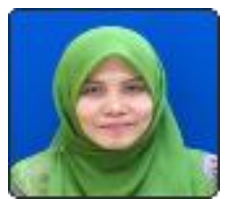

Siti Nooraiin Mohd Razali currently serve as a Lecturer in the Department of Civil Engineering at Centre for Diploma Studies (CeDS), Universiti Tun Hussein Onn Malaysia (UTHM). She graduated from Universiti Tun Hussein Onn Malaysia (UTHM) in Master of Civil Engineering and pursuing her PhD in the same field, major in Geotechnical Engineering. She has involved in 6 research grants as co-researcher and also as main researcher. She has written 20 proceeding papers, journal papers and published 2 chapters in book of Sustainable Civil Engineering Technical Papers Series 1 and Sustainable Civil Engineering Technical Papers Series 2. Her current research interest is peat soil, soil stabilization and physical model study.

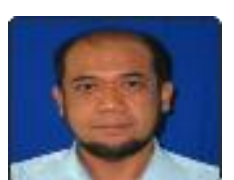

Masiri Kaamin is a Masters holder in Land Surveying (Geomatics), specialty in Geographic Information System. He graduated from Universiti Teknologi Malaysia in the year 1989 (Bachelor of Surveying) and 2001 (Master of Science). Since 2001, he has been involved in publication of more than 80 journals and proceeding articles, books and book chapters as main- and co-authors in various Geomatics and Civil Engineering areas. Of these, 42 are SCOPUS indexed articles. He has been also involved in 25 research grants as main- and co-researcher, funded by the Universiti Tun Hussein Onn Malaysia (UTHM) and Malaysian Ministry of Education. He is a Graduate member of Malaysian Board of Technologies (MBOT). He is recognized as a Professional Technologist (Ts) from MBOT since 2018 under the field of Resource Based, Survey \& Geomatics Technology. He is currently holding a post as Associate Professor in UTHM and keep on fully dedicating in teaching, supervising, research and publication for the sake of current and future generation.

Siti Noraiza AB Razak received her PhD. in Science (Physics) majoring in Laser Application Technologies, graduated from Universiti Teknologi

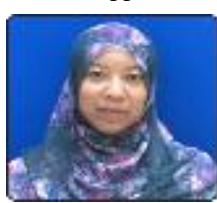
Malaysia (UTM) in 2015. Currently work as a Physics lecturer in Centre for Diploma Studies, Universiti Tun Hussein Onn Malaysia (UTHM). She received her MSc Science (Physics) in 2011 and Bachelor of Science (Health Physics) in 2009 from UTM. She is also acts as an Associate Researcher at Microelectronics and Nanotechnology-Shamsuddin Research Centre (MiNT-SRC) UTHM and have been actively involved in research since 2011 as Research Assistant and been involved as committee member for International Laser Technology \& Optic Symposium LATOS in 2014. Her areas of research interest covers various field such as laser applications, material science (thin films), nanomaterials, and green energy technology. Currently involved with several grant projects under the university sponsorship and MOE as the head of researcher and also co-researcher, mainly focus on green energy technologies. Apart from teaching, she is also committed in journal paper and book chapters writing, and has been published in Scopus Indexed Journal, WOS, and proceeding articles.

Nor Baizura Hamid is a Bachelor holder in Civil Engineering with Honors which was graduated in 2009 from Universiti Tun Hussein Onn Malaysia. She is currently a Civil Engineering Lecturer in UTHM with 8 years experience. She

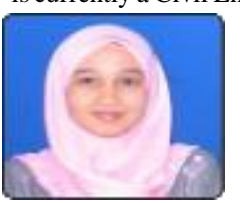
has published more than 20 articles in journals and conference proceedings as main author and co-author for the last 5 years. Of these, 15 are SCOPUS indexed articles. She has been also involved in many researches starting from 2013 until now. She has involved in 11 research grants as main- and co-researcher, funded by the Universiti Tun Hussein Onn Malaysia (UTHM) and Malaysian Ministry of Education. She also a Graduate member of Malaysian Board of Engineering (BEM) from 2011. She is currently holding a post as Instructor Engineer in UTHM and keeps on fully dedicating in teaching, supervising, research and publication for the sake of current and future generation.

Nor Farah Atiqah Ahmad has received the B.Eng, M.Eng degrees from Universiti Teknologi Malaysia in 2011 and 2013 respectively and pursuing her phd in Hydrology from the same institute. She is currently a fellow lecturer at

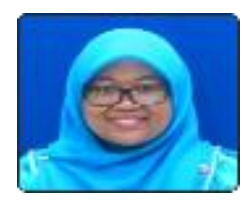
Department of Civil Engineering, Centre for Diploma Studies (CeDS), niversiti Tun Hussein Onn Malaysia (UTHM) since 2016. Her main areas of research interest include hydrology-evapotranspiration, modeling and their application in managing water balance system. She is the member of 4 active research grant and 1 head researcher funded by UTHM CeDS students received a broad background in civil engineering in which she has managed more than 20 final year project students that covers various project from environmental, structure materials, road pavement and modeling. She has presented papers at international conferences, published articles and papers in various journals and contributed a chapter to the Sustainable Civil Engineering Technical Papers: Series 1 (UTHM, 2018) main and co-authors in various Civil Engineering areas.

Mardiha Mokhtar is a Masters holder in Civil Engineering graduated from Universiti Tun Hussein Onn Malaysia (UTHM) in 2011. Her field of specialty is Geotechnical Engineering. She was a Civil Engineer at Public Works Department and in 2013, she joined the UTHM as a Lecturer. Since 2012 she

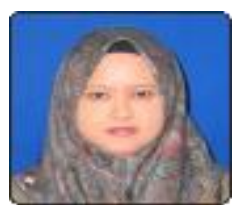
has been involved in publication of more than 20 journals and proceeding articles, books and book chapters as main and co-authors and been awarded as Outstanding Paper Award by Academic Research Society of Malaysia in 2018. Since 2015, she has involved in 4 research grants as main and co-researcher, funded by the Universiti Tun Hussein Onn Malaysia (UTHM). Her current research interests include soil stabilization, coastal erosion and UAV applications. Her teaching topic involved Geotechnical Engineering, Drawing Engineering, Static and Dynamic, Mechanics of Materials and Construction Engineering. She is currently a Lecturer in UTHM and associate researcher at Centre of Applied Geomatics for Disaster Prevention (CAGeD), Faculty of Civil and Environmental Engineering, UTHM.

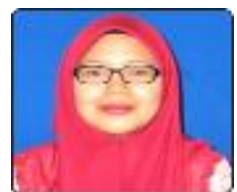

Ts. Dr. Norhayati Ngadiman served as a Head of Civil Engineering Department at Centre for Diploma Studies (CeDS), Universiti Tun Hussein Onn Malaysia (UTHM). She is a Ph.D holder in Environment and Development from Universiti Kebangsaan Malaysia. She appointed as senior researcher at Pusa Kecemerlangan Technical and Vocational Education Training (TVET). She is recognized as a Professional Technologist (Ts) from MBOT since 2018 under the field of green technology. She has become as lead researcher/co-researcher in more than10 research grants funded by the Universiti Tun Hussein Onn Malaysia (UTHM) and Malaysian Ministry of Education.

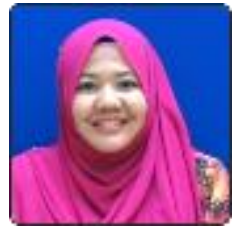

Suhaila Sahat highest education level is Master Bachelor in Hydrology and Water Resources from Universiti Teknologi Malysia.Suhaila Sahat currently works at the Department of Civil Engineering (JTKA), Universiti Tun Hussein Onn Malaysia and have served as Lecturer for 4 years and had served as Research Officer in Universiti Teknology Malaysia and involved several grant project involving project with PETRONAS and Ministry Of Argriculture. Suhaila does research in Civil Engineering. Their current project is 'EFFECT OF CLIMATE CHANGE ON THE FLOW REGIME OF SUNGAI JOHOR'. Her expertise is in Rainfall Modelling, Watershed Hydrology, Water surface hydrology and Water Resources Management. 